\title{
DE LA DESJUDICIALIZACIÓN \\ A LA REFUNDACIÓN \\ DE LOS DERECHOS \\ Transformaciones en las disputas \\ por los derechos de los niños y las niñas \\ (2005-2015)
}

De la desjudicialización a la refundación de los derechos.

Transformaciones en las disputas por los derechos de los niños y las niñas $(2005-2015)$

Pilar Anastasía González

Universidad Nacional de Córdoba, Argentina

LLobet, V., \& Villalta, G. (2019). De la desjudicialización a la refundación de los derechos. Transformaciones en las disputas por los derechos de los niños y las niñas (2005-2015).

Teseo. https://dx.doi.org/10.1160o/rlcsnj.20.1.Eo8

"Correo electrónico: pilianastasia@gmail.com 
El problema de la infancia para los estados nación contemporáneos no cesa de tematizarse y politizarse en muchos discursos de la cultura: ya sea en las agendas estatales - desde políticas sociales y/o arquitecturas punitivas-, pero también en enunciadorxs más amplios, que incluyen al mercado, los medios masivos de comunicación, las industrias culturales, la sociedad civil. Estas tematizaciones, sumamente heterogéneas, sin embargo redundan en un espacio común: configurar a la infancia como un objeto de disputa, con diversas axiologías que sustentan la contienda. Algunos elementos históricos permiten desentrañar cómo es que, a finales del siglo XX y comienzos del siglo XXI, la figuración de la infancia deviene en una nueva sensibilidad a nivel global: la firma del consenso de Washington, la financiación de las deudas de los países del Sur por el Fondo Monetario Internacional, la escalada profundización de las desigualdades y el crecimiento de la pobreza extrema coinciden con el establecimiento de la pobreza infantil como una de las agendas prioritarias de los estados. Además, de manera paralela, se da el proceso de debate y sanción de la Convención de los Derechos del Niño, que inaugura una nueva retórica para nombrar las necesidades de niñxs, desplazando los sentidos asociados a la protección social del Estado de Bienestar para instalar y legitimar el lenguaje de los derechos humanos como hegemónico para dicha tarea.

Estos procesos, densos, heterogéneos y complejos, no son lineales ni tienen un modo determinado de materializarse en diversos contextos. Desde esta consideración sobre el funcionamiento de las relaciones de poder se construye el propósito del libro, que consta de abordar los procesos de institucionalización de los derechos de niñxs y jóvenes específicamente en Argentina, y los efectos y transformaciones que ese proceso produjo tanto en el ámbito institucional jurídico y burocrático- como también social. Para ello, encontramos artículos de análisis más generales, como también análisis más micro situados que dan cuenta de estos procesos en diversas escalas.

El libro cuenta con tres grandes secciones. En la primera, llamada Transformaciones institucionales, se busca dar cuenta de las transformaciones institucionales, burocráticas y administrativas que implicó en Argentina la creación e implementación del Sistema de Protección de Derechos. Aquí se destaca el análisis interpretativo de procesos sociales y normativos recientes: el libro aborda las transformaciones desde la sanción de la ley Protección 26.061 en el año 2005, pero historiza desde mediados de los años go para reconstruir la condiciones de posibilidad de la ley. Así mismo, sitúa el alcance hasta el año 2015 que finaliza el gobierno kirchnerista, aunque también incluye elementos del cambio de gobierno que caracterizaron a la gestión ejecutiva del 2015 hasta 2019 -presidida por Macri e 
inscripta en transformaciones sobre el rol del estado significativas respecto de la gestión previa-. Fuera de este período que limita al objeto del estudio del libro de manera formal, podemos inferir una concepción y análisis de la temporalidad de los procesos sociales que permiten ir y venir en la historia de los sentidos, que desplazan consideraciones lineales del tiempo cronológico, al modo en el que Williams conceptualizó el funcionamiento social de elementos emergentes, residuales y dominantes. Estas consideraciones sitúan de manera relevante una discusión implícita con las ideas de cierta evolución de la cuestión de la infancia, asociada a modernizaciones en el plano económico, político y social.

Otra especificidad de la primera sección es el carácter federal del abordaje de las transformaciones institucionales y normativas, que resulta poco usual, que es urgente y que está en crecimiento en las Ciencias Sociales. Este abordaje, esencial teniendo en cuenta el diseño federal de la gestión gubernamental argentina y los procesos de descentralización, permite señalar las diferencias de enfoques, perspectivas y tratamientos estatales de cada provincia respecto de la infancia. Las capacidades administrativas, de gestión, los recursos presupuestarios disponibles, los sentidos comunes hegemónicos de las comunidades locales, las memorias institucionales de los órganos gobiernos provinciales, la formación de lxs agentes y funcionarixs, el diseño de políticas sociales específicas, son todos elementos diferenciales territorialmente pero centrales a la hora de analizar la implementación, tratamiento, y materialización de derechos en el territorio nacional.

El artículo que encabeza la sección realiza un mapeo imprescindible para cualquier lectorx advenedizo al campo de estudios sociales de infancia, poniendo de relieve los elementos centrales del Sistema de Protección de Derechos -históricos, pero también contemporáneos, en diferentes escalas y en diversas dimensiones. Luego, se encuentra proseguido de abordajes que complementan el análisis nacional dándole la carnadura localizada: abordajes de trasformaciones institucionales en provincia de Buenos Aires, en Santa Fe, en Jujuy, y el análisis de casos de Mendoza y San Juan cuyas normativas relativas a la infancia fueron pioneras al incorporar los términos de la Convención aun antes de que se sancione la ley nacional de protección en 2005 .

La segunda parte del libro titulada Actores, prácticas, moralidades y sensibilidades presenta los análisis en una escala más micro, pero no por eso menos relevantes o significativas, siendo que este plano de análisis explicita el funcionamiento de normas - moralidades y sensibilidades - que informan las medidas, decisiones y políticas que finalmente se toman en casos y escenarios concretos sobre niñxs y sus familias. Así, las interpretaciones de las necesidades de niñxs y adolescentes por 
parte de agentes estatales — en sentido amplio-y/o funcionarixs del gobierno forman parte central del aparato de implementación del Sistema de Protección. La relación entre agentes estatales con los marcos normativos y las redes políticas sobre las que se asientan los procesos de institucionalización son tan relevantes de ser estudiados como como el aparato legal que lo sustenta.

Así mismo, la sección nos sitúa ante un debate clásico del giro afectivo, no explicitado en el libro de manera directa pero sí trabajado de manera integral: la consideración no excluyente de que las emociones forman parte intrínseca de las estructuras políticas. Esto es, el análisis de las emociones no forma parte de un añadido, al modo de caracterización de las conductas de lxs agentes por ejemplo, sino que dan forma, son gramáticas intrínsecas y estructurales de la toma de decisiones en los ámbitos administrativos y judiciales que dirimen la potestad sobre lxs niñxs. Esto implica un marco que podemos inscribir en la obra de Lauren Berlant (1997), en la que se propone un cambio de consideración teórico sobre la emocionalidad: no se trata de analizar los modos de subjetivación mediante el análisis de prácticas culturales, sus negociaciones y las resistencias - Berlant se refiere aquí, por ejemplo, al modo en que Sedgwick (1998) abordó la vergüenza asociada de modo directo como un modo de opresión- sino que se trata de enfocar a la intimidad y a los afectos como claves de lectura para analizar la constitución de los significados de lo considerado público, nacional, y ciudadano. En palabras de las autoras del último capítulo de la sección, «aquí hemos buscado enfocar no tanto en las prácticas institucionales como portadoras de emociones, sino en la misma política de las emociones que ordena y legitima desigualdades y relaciones de poder en el campo, reactualizando asimetrías y posiciones morales» (Llobet \& Villalta, 2019, p. 374). Las estructuras políticas son también estructuras emocionales.

La tercera parte del libro aborda los arreglos y gestiones estatales en torno a la justicia penal juvenil y al acogimiento familiar. Con respecto a la justicia penal juvenil, se destaca el tratamiento no homogeneizado del estado - la premisa atraviesa todo el libro - en tanto cada arreglo institucional específico define necesidades que devienen legítimas y, por ende, otras que no. En el ámbito de los castigos penales, la administración de la minorización y la distribución de las capacidades de responsabilidad son diferenciales, moralizando a lx joven en cuestión y a las relaciones familiares del entorno. A su vez, el modo en el que se gestiona el delito juvenil funciona en una asociación entre masculinidad, riesgo y delito que ha sido ampliamente trabajada en el campo de estudios específicos. Sin embargo, estos procesos no son lineales en el conjunto de órganos dispuestos a administrar la justicia penal juvenil y el trabajo de abordaje de cómo se van 
construyendo esas sentencias, políticas y significados cobra gran relevancia, como se demuestra en la sección.

Así mismo, dentro de esta sección encontramos recorridos analíticos y temáticos que, al modo del primer capítulo del libro, resultan centrales para el campo de estudios por su densidad teórica y analítica, pero también por su eventual carácter introductorio en tanto reponen las líneas centrales de las problemáticas incorporando desde perspectivas históricas de mediana duración el modo como determinados tópicos específicos son construidos como problemas estatales, la historización de la política y/o programa en cuestión, y la dimensión de su funcionamiento situado. Así son abordados temas como el debate sobre la justicia restaurativa, la privación de la libertad de adolescentes, las transformaciones institucionales en la justicia penal juvenil y el acogimiento familiar como política pública en el país.

El campo de estudios sociales de infancia, con un acumulado de más de tres décadas de investigaciones sostenidas y contundentes en Argentina y en la región, ha analizado las argumentaciones que construyen un lugar especial para la infancia en la sociedad. Inscripto en ese marco, el libro toma en cuenta no sólo la dimensión global de organización de los problemas, necesidades y tensiones esbozadas como problemas de la infancia, sino también, y especialmente, la dimensión localizada en la que estos discursos y políticas son materializados. Ahora bien, el análisis de los procesos de institucionalización y/o materialización — podríamos decir también sedimentación desde un punto de vista más discursivo- es realizado mediante operaciones heurísticas que se encuentran lejos de un extendido modo de producir conocimiento en los campos de las ciencias sociales y humanas que se preguntan, con un horizonte moral que tiñe el final de la pesquisa, si determinados procesos (sociales, políticas, o discursos) reproducen o subvierten normas o relaciones de poder. Esto es, un binarismo heurístico que conduce a las investigaciones - aún aquellas que discuten el binario que puede caracterizar a sus objetos de estudio- a señalar posicionamientos excluyentes, reductivos, totalizantes y jerárquicos al modo de la ya largamente discutida hipótesis represiva del poder foucaultiana.

Los trabajos del libro nos invitan a pensar de otro modo. Nos invitan a navegar tensiones, diálogos, continuidades, paradojas, rupturas, desplazamientos, solapamientos, yuxtaposiciones y otras operaciones que dan cuenta de un modo de tejer las relaciones estatales-sociales-culturales-económicas desde una trama de la complejidad. Esto se ata a la capacidad de la investigación de articular las diferentes dimensiones con el tratamiento de escalas de investigación que van de lo micro a lo macro sin perder de vista la importancia de ambos polos, y el abanico de matices entre ambos, como constitutivos de las relaciones de poder que se están analizando. 
Esto hace que el libro sea, per se, un atractivo para ser leído aun cuando lx lectorx no posea intereses específicos en el campo de la infancia.

Junto al valor epistemológico y metodológico recién señalado, yace el valor político de su comunicabilidad, siendo que se trata de una escritura producida para ser accesible a destinatarixs heterogénexs, sin por ello perder la perspectiva de la complejidad como premisa de los análisis.

\section{Referencias}

Berlant, L. (1997). The queen of America goes to Washington city. Essays on sex and citizenship. Duke University Press.

LLobet, V., \& Villalta, C. (2019). De la desjudicialización a la refundación de los derechos. Transformaciones en las disputas por los derechos de los niños y las niñas (2005-2015). Teseo.

Sedwick, E. K. (1998). Epistemología del armario. Ediciones de la Tempestad. 